\title{
Proceeding Paper \\ Implementation of Metallic Film Electrodes for Catalytic Adsorptive Stripping Voltammetric Determination of Germanium(IV) ${ }^{\dagger}$
}

\author{
Agnieszka Królicka *, Jerzy Zarębski and Andrzej Bobrowski
}

check for

updates

Citation: Królicka, A.; Zarębski, J.; Bobrowski, A. Implementation of Metallic Film Electrodes for Catalytic Adsorptive Stripping Voltammetric Determination of Germanium(IV). Chem. Proc. 2021, 5, 7. https:// doi.org/10.3390/CSAC2021-10484

Academic Editor: Núria Serrano

Published: 30 June 2021

Publisher's Note: MDPI stays neutral with regard to jurisdictional claims in published maps and institutional affiliations.

Copyright: (c) 2021 by the authors. Licensee MDPI, Basel, Switzerland. This article is an open access article distributed under the terms and conditions of the Creative Commons Attribution (CC BY) license (https:/ / creativecommons.org/licenses/by/ $4.0 /)$.
Department of Building Materials Technology, Faculty of Materials Science and Ceramics, AGH University of Science and Technology, Mickiewicza 30, 30-059 Krakow, Poland; zarebski.jerzy@gmail.com (J.Z.); abobrow@agh.edu.pl (A.B.)

* Correspondence: krolicka@agh.edu.pl

+ Presented at the 1st International Electronic Conference on Chemical Sensors and Analytical Chemistry, 1-15 July 2021; Available online: https: / / csac2021.sciforum.net/.

\begin{abstract}
In the present work, it has been shown that bismuth film electrodes deposited on screenprinted carbon supports could be successfully used to provide well-shaped, sensitive and reproducible catalytic adsorptive stripping signals of $\mathrm{Ge}(\mathrm{IV})$ in the presence of catechol and V(IV)-HEDTA (HEDTA-N-hydroxyethyl-ethylene diamine-triacetic acid) complex.
\end{abstract}

Keywords: film electrodes; germanium; stripping voltammetry

\section{Introduction}

Germanium represents a unique group of elements known as Critical Raw Materials (EU). Although such elements typically constitute only a small percentage of a material by weight, they are essential to its performance [1]. Among the numerous analytical techniques available, voltammetry seems to have much to offer in this regard, as voltammetric techniques are insensitive to the presence of inorganic salts and, at the same time, they offer low detection limits. Among voltammetric methods, catalytic adsorptive stripping voltammetry (CAdSV) plays an essential role in trace analysis due to its remarkable sensitivity. To induce a catalytic effect which gives the method its outstanding sensitivity, ions with oxidizing properties must be added to the examined solution, e.g., nitrate, nitrite, bromate or chlorate. Unfortunately, many electrode materials, both metallic sensing layers as well as auxiliary polymers, are damaged under the influence of these oxidants.

As was reported earlier, using HMDE or silver-amalgam working electrodes and the supporting electrolyte containing V(IV)-HEDTA (HEDTA-N-hydroxyethyl-ethylene diamine-triacetic acid) complex (Figure 1), catechol or its derivatives, the well-developed germanium signals could be recorded at nM level [2,3]. To develop a workable analytical procedure for the detection of trace amounts of germanium, and to meet the current guidelines that impose limitations on the application of mercury in chemical and analytical laboratories, an environmentally friendly alternative should be employed instead. The metallic film electrodes, such as bismuth (BiFE) and lead (PbFE) electrodes are among the most widely used sensors in the field of stripping voltammetry [4].

This work aims to assess the applicability of lead and bismuth film electrodes deposited electrochemically or by physical deposition from gaseous phase on different supports to provide catalytic adsorptive stripping signals of Ge(IV) in the presence of catechol and V(IV)-HEDTA complex. 


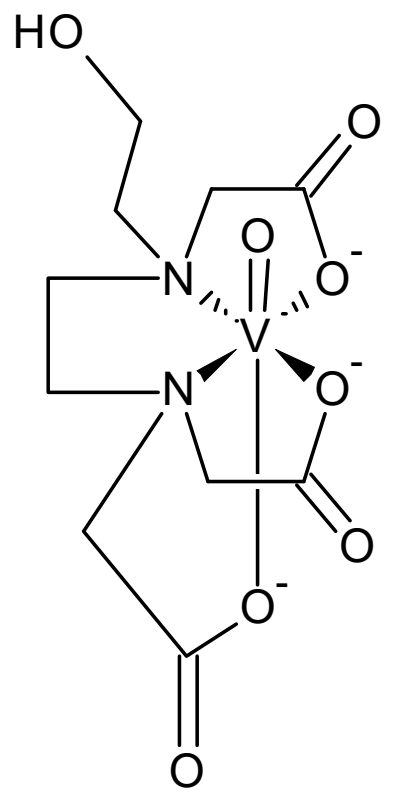

Figure 1. The structure of V(IV)-HEDTA complex.

\section{Materials and Methods}

Electrochemical study was performed on a Autolab 204 analyzer (Metrohm Autolab B.V., Utrecht, The Netherlands). Disposable screen-printed electrodes (4 mm diameter) (DropSens, Oviedo, Spain) or disc electrodes (3 mm diameter) made of glassy carbon or gold (Mineral, Łomianki-Sadowa, Poland) were used as supports for bismuth films. Platinum wire and $\mathrm{Ag} / \mathrm{AgCl}(3 \mathrm{M} \mathrm{KCl})$ were applied as the anode and reference electrodes. All applied reagents were analytical grade.

Lead and bismuth films were plated just prior to use by means of potentiostatic deposition. Before plating, the disc substrates were polished using an $\mathrm{Al}_{2} \mathrm{O}_{3}$ suspension (0.3 and $0.05 \mu \mathrm{m}$ ) applied onto a polishing cloth. Screen-printed electrodes did not require any preparation or processing other than 2 min of soaking in the plating solution immediately prior to electrolysis. The plating process performed in quiescent $0.34 \mathrm{M} \mathrm{HClO}_{4}$ containing $0.043 \mathrm{M}$ of $\mathrm{Bi}(\mathrm{III})$ or stirred $0.2 \mathrm{M}$ acetate buffer containing $0.003 \mathrm{M} \mathrm{Pb}(\mathrm{II})$ was monitored by recording chronoamperometric curves and stopped when the charge reached the defined threshold $\left(\mathrm{E}_{\text {plat }}=-0.9 \mathrm{~V}, \mathrm{Q}_{\text {plat }}=0.8 \mathrm{mC}\right.$ per $\left.\mathrm{mm}^{2}\right)$. Pre-plated electrodes were rinsed with $0.1 \mathrm{M}$ acetate buffer $(\mathrm{PbFE})$ or $0.34 \mathrm{M} \mathrm{HClO}_{4}$ (BiFE) and water. The PVD deposition followed the protocol described in the previous work [5].

The supporting electrolyte contained $0.05 \mathrm{M}$ acetate buffer ( $\mathrm{pH}$ of 4.4 ), $1 \mathrm{mM}$ of catechol, $1 \mathrm{mM}$ of V(IV) and $1.5 \mathrm{mM}$ of HEDTA. CAdSV voltammograms were recorded after $30 \mathrm{~s}$ of accumulation performed at the potential of $-0.6 \mathrm{~V}(\mathrm{PbFE})$ or $-0.4 \mathrm{~V}(\mathrm{BiFE})$ by differential pulse mode.

\section{Results and Discussion}

\subsection{Support Selection}

To deposit the metallic sensing layers, the following supports were considered: (1) carbon-based electrodes: glassy carbon, carbon paste, impregnated carbon, screen printed carbon and (2) gold-based electrodes: bulk disc, PDV deposited gold, gold screen printed. The sensing layers were deposited electrochemically by ex situ plating or by PVD deposition. The preliminary tests of freshly prepared films rinsed with water were performed by microscopic inspection. In the case of carbon-based supports and bismuth films, the visual changes were not pronounced, as the plating only gave the surface a black, velvety appearance. In the case of lead deposits, the electrode surface was turned gray. In the case of gold supports, the results were more complex. While the expected finding was that the type of the support (gold monolithic disc, gold screen printed layer, or PVD deposited 
gold) does not play the key role, this study showed that the method of support preparation plays an important role. The films deposited on the gold disc electrode were very stable and adhesive. The lead layers deposited on the SPE or PVD gold were oxidized within minutes once removed from the plating solution (Figure 2). In the case of bismuth, the oxidation at AuSPE was slower but unrelenting. Information on the mechanism of oxidation of the metallic layer was provided by analysis of the bismuth films deposited on the microscratched Au PVD layer (Figure $3 \mathrm{a}-\mathrm{c}$ ). The microscopic images revealed the bismuth crystallites formed near microscratches are susceptible to oxidation. Gradually the gold support was exposed, but after $10 \mathrm{~min}$, further changes were not observed as the bismuth crystallites adjacent to the scratches were depleted. The color histograms of microscopic images of Bi deposited on AuPVD shown in Figure 3d have not demonstrated any further changes for pictures taken 10 and $12.5 \mathrm{~min}$ after removal from the plating solution. The microanalysis performed by SEM XRF, and XRD studies of AuSPE as well as AuPVD electrodes did not reveal other elements than gold. Some insight was provided by contact angle measurements, displaying a significant difference in wettability of PVD gold $\left(68.0 \pm 0.2^{\circ}\right)$ and SPE $\left(92.0 \pm 0.3^{\circ}\right)$ electrodes. Since the surface microstructure of materials correlates closely with the apparent contact angle at the boundary between the liquid and the surface, the different surface properties of AuSPE and AuPVD were confirmed. The AuPVD contact angle value corresponds well to earlier reported values [6], while those obtained for AuSPE are substantially higher, placed on the threshold of hydrophobicity. The high contact angle can be explained by the rough three-dimensional structure of the gold layer, preventing the access of water molecules to the electrode surface by trapped air or by organic compounds of the ink used for screen printing. Regardless of cause, the gold screen printed electrodes cannot be used for bismuth or lead ex situ plating.

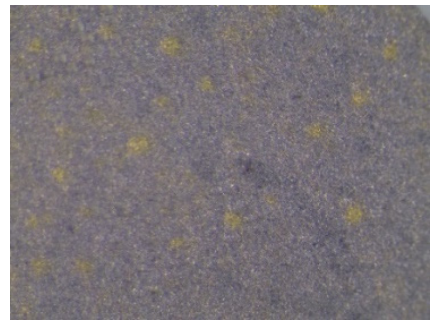

(a)

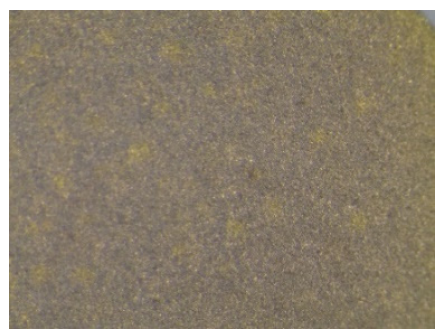

(c)

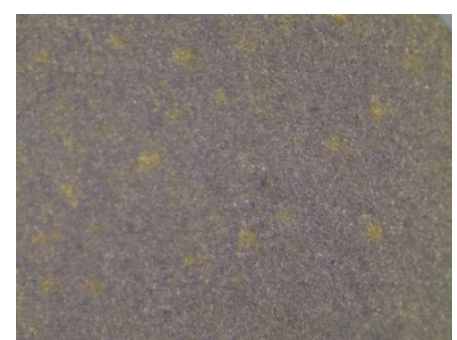

(b)

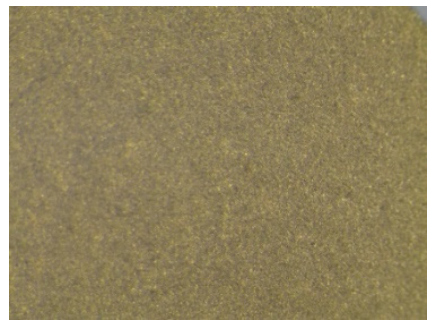

(d)

Figure 2. Microscopic images of Pb plated gold SPE recorded after 0 (a), 2.5 (b), 5 (c) and 7.5 (d) min after plating. Gray regions represent the lead layer while yellow the exposed gold support. 


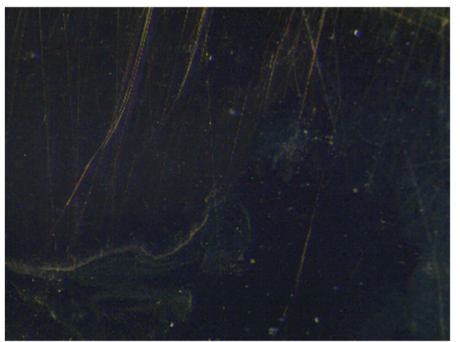

(a)

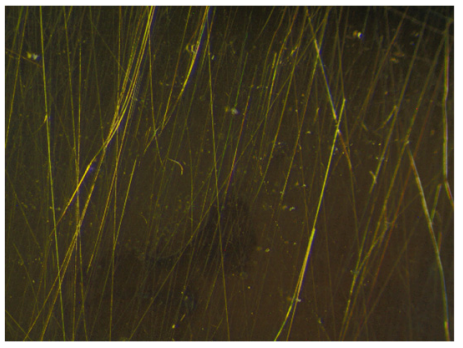

(c)

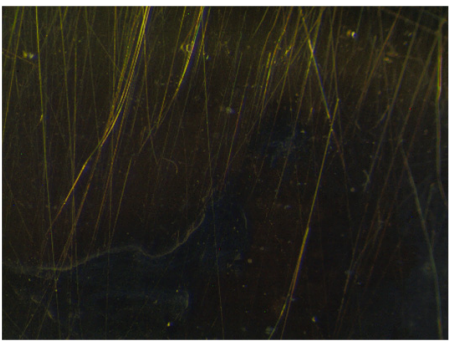

(b)

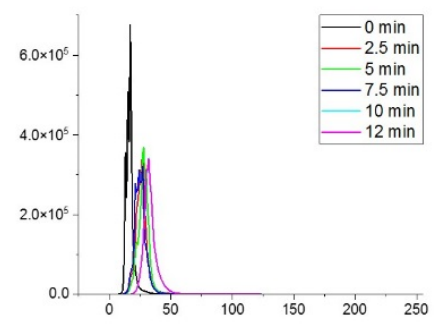

(d)

Figure 3. Microscopic images of Bi plated gold sputtered electrode recorded 0 (a), 2.5 (b) and 12 (c) min after plating (150x; images brightened to make the details more visible). Color histogram analysis of the bismuth layer plated on the sputtered gold electrode (d) (https: / / www.dcode.fr/ image-histogram, accessed on 8 June 2021).

\subsection{Stability Studies of Metallic Films in Contact with V(IV)-HEDTA Solution}

The externally plated bismuth and lead films as well as PVD deposited bismuth and lead layers were exposed to the supporting electrolyte containing the V(IV)-HEDTA complex, catechol and acetate buffer. Employing bismuth film electrodes of any type, it was possible to record well-shaped germanium signals in solutions containing from a few to several hundred $\mathrm{nM}$ of germanium. In the case of lead film electrodes, only PbFE deposited on glassy carbon, carbon paste and impregnated carbon provided measurable germanium signals. Lead layers deposited on SPE supports of any type did not deliver any germanium signals. Although the signals recorded by the most promising lead electrode, namely, $\mathrm{PbFE} / \mathrm{GC}$, in the solution containing $30 \mathrm{nM}$ of $\mathrm{Ge}(\mathrm{IV})$, were initially quite pronounced, there was no Ge(IV) signal after recording ten or so voltammograms. In this way, the unsuitability of PbFEs for their intended use in stripping voltammetry became apparent.

\subsection{Analytical Performance of Bismuth Plated Screen Printed Electrodes}

It was shown [2] that when the HMDE electrode was used as the working electrode, the catalytic activity of HEDTA vanadium complexes towards the germanium complex was correlated with the redox behavior of V(IV)-HEDTA. In the case of pyrogallol germanium complexes, the intensity of the germanium signal correlated with the characteristics of the voltammetric signal representing the reduction of the V(IV) complex [3]. The cyclic voltammograms shown in Figure $4 \mathrm{a}$ were recorded by means of bismuth plated glassy carbon and carbon SPE electrodes and compared with the curves obtained when CGMDE and GC were used. Both CGMDE and GC delivered well-shaped reversible voltammograms of V(IV)-HEDTA complex, while at BiFE electrodes only reduction signals were observed. Such behavior indicates that the catalytic process at BiFEs proceeds following a different mechanism than that observed at CGMDE.

The catalytic signals of Ge(IV) recorded at BiFE/SPE in the presence of V(IV)-HEDTA were pronounced and highly reproducible, as it is shown in Figure $4 \mathrm{~b}$. The calibration curve is given by the equation $y=(0.083 \pm 0.001) x+(0.06 \pm 0.01)\left(r^{2}=0.9989\right)$, where $y$ and $x$ denote the peak current $(\mu \mathrm{A})$ and $\mathrm{Ge}(\mathrm{IV})$ concentration $(\mathrm{nM})$. The $\mathrm{I}_{\mathrm{p}}=\mathrm{f}\left(\mathrm{c}_{\mathrm{Ge}(\mathrm{IV})}\right)$ is linear within the range from 2 to $30 \mathrm{nM}(\mathrm{LOD}=1.5 \mathrm{nM})$. Finally, BiFE/SPEs were applied 
for Ge(IV) determination in Ge(IV) spiked snow water $(10 \mathrm{nM})$ via the standard addition method and the concentration of $10.05 \pm 0.11 \mathrm{nM}$ was determined.

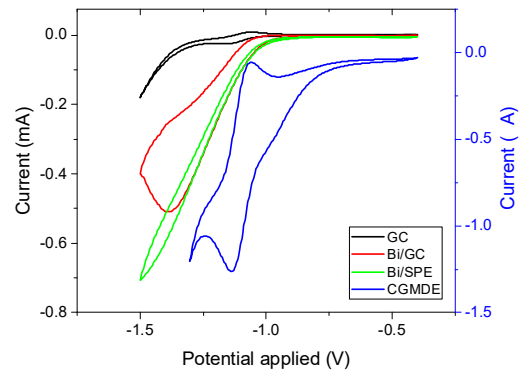

(a)

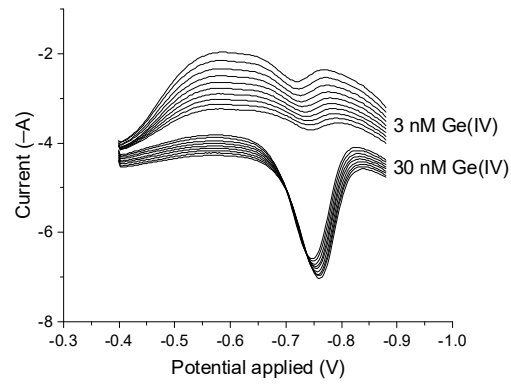

(b)

Figure 4. $\mathrm{CV}$ voltammograms recorded in an $0.05 \mathrm{M}$ acetate buffer containing $1 \mathrm{mM}$ of $\mathrm{V}(\mathrm{IV})$ and $2 \mathrm{mM}$ of HEDTA using glassy carbon (GC), bismuth plated glassy carbon (BiFE/GC), bismuth plated screen printed carbon electrode (BiFE/SPE) and a controlled-growth mercury drop electrode (CGMDE). Scan rate $=50 \mathrm{mVs}^{-1}$ (a). Ten consecutive differential pulse voltammograms recorded by $\mathrm{Bi} / \mathrm{SPE}$ electrode in the solution containing 3 or $30 \mathrm{nM}$ of $\mathrm{Ge}(\mathrm{IV})$ and $0.05 \mathrm{M}$ acetate buffer ( $\mathrm{pH}$ of 4.4), $1 \mathrm{mM}$ of catechol, $1 \mathrm{mM}$ of $\mathrm{V}(\mathrm{IV})$ and $1.5 \mathrm{mM}$ of HEDTA (b).

\section{Conclusions}

The results reported here demonstrate that the properties of lead and bismuth film electrodes differ considerably and only bismuth plated electrodes enable germanium analytical signals to be obtained when Ge(IV)-catechol-V(IV)-HEDTA system is employed.

Author Contributions: Conceptualization, A.K.; methodology, A.K.; software, A.K.; writingoriginal draft preparation, A.K.; writing-review, A.B. and J.Z.; visualization, A.K. All authors have read and agreed to the published version of the manuscript.

Funding: This work was supported by the subsidy of the Ministry of Education and Science for the AGH University of Science and Technology in Kraków (Project No 16.16.160.557).

Institutional Review Board Statement: Not applicable.

Informed Consent Statement: Not applicable.

Data Availability Statement: The data are available on request from the corresponding author, (A.K.).

Conflicts of Interest: The authors declare no conflict of interest.

\section{References}

1. Eggert, R.G. Minerals go critical. Nat. Chem. 2011, 3, 688-691. [CrossRef] [PubMed]

2. Zarębski, J.; Bobrowski, A.; Gonciarczyk, J.; Królicka, A. Extremely sensitive germanium stripping voltammetric determination with the use of a new Ge (IV)-catechol-V(IV)-HEDTA catalytic adsorptive system. Electrochim. Acta 2019, 324, 134859. [CrossRef]

3. Zarębski, J.; Bobrowski, A.; Gonciarczyk, J.; Królicka, A. Selection of Optimal Ligand and Vanadium (IV) Complexonate for Sensitive Catalytic Adsorptive Stripping Voltammetric Quantification of Germanium. Electroanalysis 2020, 32, $2213-2219$. [CrossRef]

4. Economou, A. Screen-printed electrodes modified with "green" metals for electrochemical stripping analysis of toxic elements. Sensors 2018, 18, 1032. [CrossRef] [PubMed]

5. Bobrowski, A.; Królicka, A.; Śliwa, J.; Zarębski, J.; Januś, M.; Kyzioł, K. PVD fabrication of lead film electrodes and their catalytic adsorptive stripping voltammetric performance in the presence of oxidants. Electrochem. Commun. 2018, 94, 49-54. [CrossRef]

6. Canning, J.; Tzoumis, N.; Beattie, J.K.; Gibsonc, B.C.; Ilagand, E. Water on Au sputtered films. Chem. Commun. 2014, 50, 9172-9175. [CrossRef] [PubMed] 